\title{
e-Migrinter
}

15 | 2017

Migrinter a trente ans : analyses et portraits

\section{Portrait de Carole Tardif, technicienne en documentation et édition, bureau 017}

Carole Tardif

\section{(2) OpenEdition \\ Journals}

Édition électronique

URL : https://journals.openedition.org/e-migrinter/838

DOI : 10.4000/e-migrinter.838

ISSN : 1961-9685

Éditeur

UMR 7301 - Migrinter

Référence électronique

Carole Tardif, « Portrait de Carole Tardif, technicienne en documentation et édition, bureau 017 », eMigrinter [En ligne], 15 | 2017, mis en ligne le, consulté le 20 mai 2021. URL : http://

journals.openedition.org/e-migrinter/838; DOI : https://doi.org/10.4000/e-migrinter.838

Ce document a été généré automatiquement le 20 mai 2021.

Tous droits réservés 


\title{
Portrait de Carole Tardif, technicienne en documentation et édition, bureau 017
}

\author{
Carole Tardif
}

\section{NOTE DE L'ÉDITEUR}

Ce billet fait partie d'une série de quatre portraits réalisés à partir d'un questionnaire initié par Sarah Przybyl et Julie Lemoux.

Quel est ton poste et depuis combien de temps travailles-tu au laboratoire? Que faisais-tu avant de travailler à Migrinter?

Je suis technicienne en documentation et en Publication assistée par ordinateur (PAO) depuis 9 ans au sein de Migrinter. Avant d'intégrer le laboratoire, j'étais aidedocumentaliste dans des bibliothèques universitaires (en médecine pharmacie, en géographie) et j'ai aussi travaillé au secrétariat de la direction régionale des affaires culturelles (DRAC).

Comment définirais-tu ta mission au laboratoire Migrinter?

Je fais partie de ce que l'on appelle l'appui à la recherche.

Mes missions recouvrent plusieurs domaines de compétences (l'information scientifique et technique; l'édition) afin d'aider à valoriser et diffuser la recherche.

Pourrais-tu nous décrire en quelques mots une journée-type?

Elle commence par la lecture de mes mails, continue avec une pause café et se termine par un petit tour au centre de documentation. Entre tout cela, j'effectue le travail quotidien inhérent à la vie d'une bibliothèque, je gère les aspects techniques de la publication de la revue du laboratoire (e-Migrinter) et les différentes demandes formulées par des doctorants ou des chercheurs.

Une journée bien remplie! 
Peux-tu nous faire part d'un événement, d'une anecdote ou d'une rencontre qui, au cours de ton expérience à Migrinter, ont marqué ta carrière et/ou ta vision des migrations internationales?

Mon travail sur les 47 photos du camp de réfugiés d'Ukwimi en Zambie avec Véronique Lassailly-Jacob. Je ne savais pas à quoi cela pouvait ressembler avant, ni comment on pouvait organiser le regroupement des réfugiés, leur vie à l'intérieur du camp, après le camp. Je ne m'étais jamais posée ce genre de questions. J'ai appris beaucoup de choses.

As-tu été marqué par un (ou plusieurs) événement en particulier au cours de ta carrière à Migrinter? (évolution de poste, arrivée/départ d'un collègue, changement direction, etc.)

J'ai récemment réussi un examen professionnel. Grâce au coup de main d'une partie de l'équipe, j'ai réalisé ma meilleure prestation orale. Il a fallu un bon coaching, motivant et sans pression, pour que je décroche cette promotion ... et pour moi c'est une performance !!!

Pourrais-tu donner trois mots qui définissent Migrinter à tes yeux?

Équipe, microcosme, causerie.

\section{UNE IMAGE}

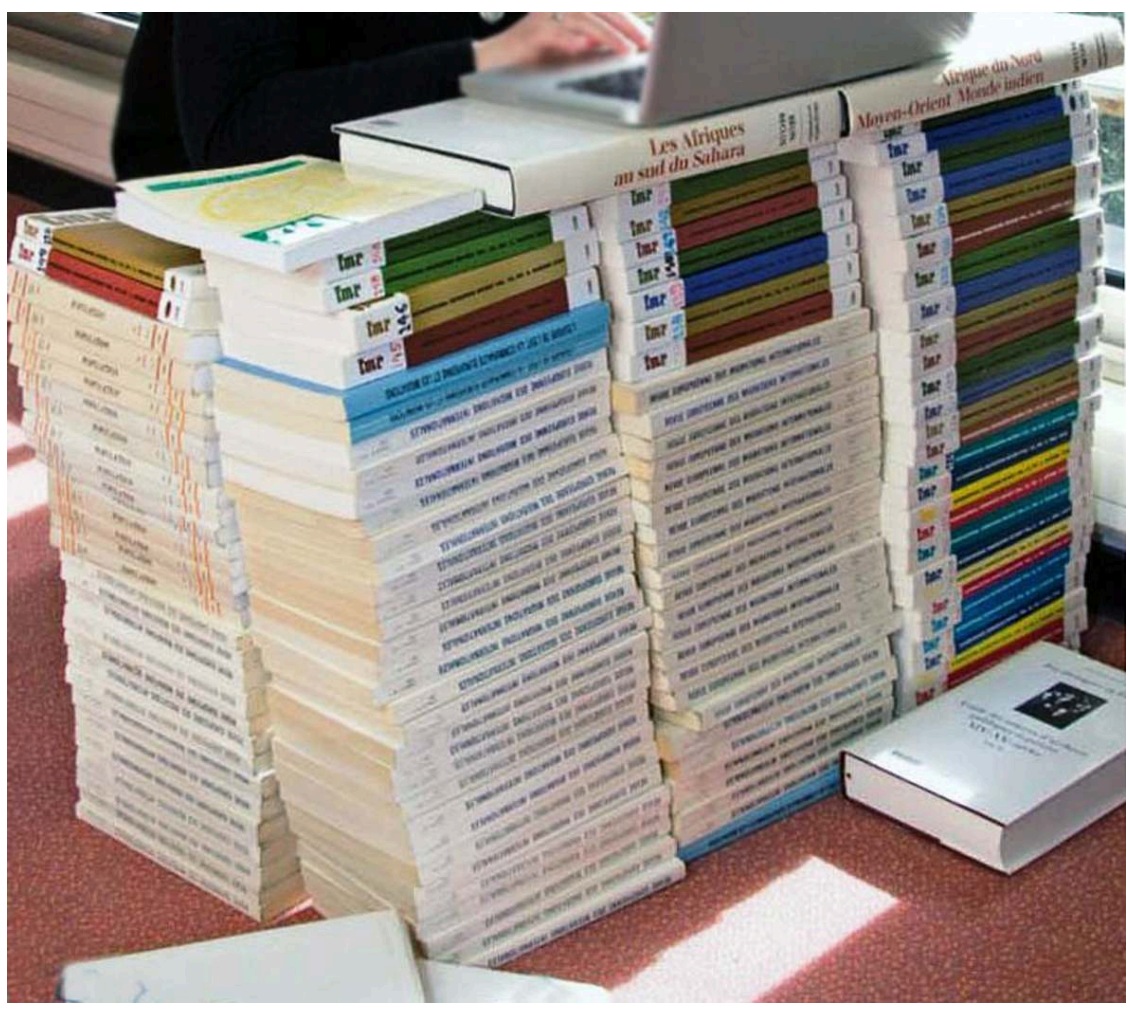

1 Cette photo a été prise par Sébastien Degguy (Ingénieur plateforme numérique, photographe) 3 ans après mon arrivée à Migrinter. Elle contient tout ce dont je me sers dans mon travail: l'ordinateur, les livres; mais surtout, elle montre la quantité de documents à traiter. Elle m'évoque aussi que l'on peut s'amuser de temps en temps à la bibliothèque, surtout quand on recrute pour ranger après! 


\section{AUTEUR}

\section{CAROLE TARDIF}

Technicienne supérieure au CNRS, Migrinter - UMR 7301, CNRS / Université de Poitiers carole.tardif@univ-poitiers.fr 